7 Heckmann M, Breit S, Ceballos-Baumann A, Schaller M, Plewig G. Sidecontrolled intradermal injection of botulinum toxin type A in recalcitrant axillary hyperhidrosis. J Am Acad Dermatol 1999;41:987-90.

8 Naumann M, Flachenecker P, Bröcker E-B, Toyka KV, Reiners K. Botulinum toxin for palmar hyperhidrosis. Lancet 1997;349:252.

9 Naumann M, Hofmann U, Bergmann I, Hamm H, Toyka KV, Reiners K. Focal hyperhidrosis: effective treatment with intracutaneous botulinum toxin. Arch Dermatol 1998;134:301-4.

10 Naver H, Swartling C, Aquilonius S-M. Treatment of focal hyperhidrosis with botulinum toxin type A. Brief overview of methodology and 2 years experience. Eur J Neurol 1999;6(suppl 4):S117-20.

11 Odderson IR. Hyperhidrosis treated by botulinum A exotoxin. Dermatol Surg 1998;24:1237-41.

12 Odderson IR. Axillary hyperhidrosis: treatment with botulinum toxin type A. Arch Phys Med Rehabil 1998;79:350-2.

13 Schnider P, Binder M, Berger T, Auff E. Botulinum A toxin injection in focal hyperhidrosis. Br J Dermatol 1996;134:1160-1.

14 Schnider P, Binder M, Kittler H, Birner P, Starkel D, Wolff K, et al. A randomized, double-blind, placebo-controlled study trial of botulinum toxin type A for severe hyperhidrosis. Br J Dermatol 1999;140:677-80.
15 Shelley WB, Talanin TY, Shelley ED. Botulinum toxin therapy for palmar hyperhidrosis. J Am Acad Dermatol 1998;38:227-9.

16 Minor V. Ein neues Verfahren zu der klinischen Untersuchung der Schweissabsonderung. Dtsch Z Nervenheilkd 1927;101:301-6.

17 Bushara KO, Park DM, Jones JC, Schutta HS. Botulinum toxin-a possible new treatment for axillary hyperhidrosis. Clin Exp Dermatol 1996;21:276-8.

18 Drott C, Gothberg G, Claes G. Endoscopic transthoracic sympathectomy: an efficient and safe method for the treatment of hyperhidrosis. J Am Acad Dermatol 1995;33:78-81.

19 Drott C, Claes G. Hyperhidrosis treated by thoracic sympathectomy. Cardiovasc Surg 1996:4:790-1.

20 Lai YT, Yang LH, Chio CC, Chen HH. Complications in patients with palmar hyperhidrosis treated with transthoracic endoscopic sympathectomy Neurosurgery 1997;41:110-3.

21 Kao MC, Chan YL, Lin YJ, Hsieh CA, Tsai JC. Endoscopic sympathectomy treatment of craniofacial hyperhidrosis. Arch Surg 1996;131:1091-4

22 Herbst F, Plas EG, Fugger R, Fritsch A. Endoscopic thoracic sympathectomy for primary hyperhidrosis of the upper limbs: a critical analysis and long-term results of 480 operations. Ann Surg 1994;220:86-90.

(Accepted 5 July 2001)

\title{
Social factors associated with child mental health problems in Brazil: cross sectional survey
}

\author{
Bacy Fleitlich, Robert Goodman
}

The prevalence of child psychiatric disorder in the developed world is $10-20 \%$, but in the developing world, where children and adolescents make up a higher proportion of the population, the prevalence may be higher. ${ }^{1}$ Relatively little is known about the extent to which social risk factors identified in the developed world also apply in the developing world. ${ }^{1}$ To guide healthcare planning we used three contrasting samples from the largest and most populous country in Latin America to examine the association between child mental health problems and social factors, such as poverty, family violence, and parental mental illness.

\section{Participants, methods, and results}

Three contrasting neighbourhoods were selected from a single district in south east Brazil: a new favela (shanty town) of crowded makeshift dwellings, lacking sanitation, and built on illegally occupied land; a stable urban community; and a rural village. We aimed to identify all 7-14 year olds (compulsory school years) in these three areas from school registers. For the children on school lists, we obtained informed parental agreement to participation for $75 \%$ of the children from the favela, $67 \%$ from the stable urban community, and $95 \%$ from the rural village. Supplementary house to house searches in the favela identified relatively few additional 7-14 year olds who were not on any school list-amounting to only $16 \%$ of the favela sample and not differing significantly in social or psychiatric characteristics. The total sample of 898 participating children comprised 488 from the favela, 346 from the stable urban area, and 64 from the rural area.

Children with probable psychiatric disorder were identified by parents, teachers, and self report versions of the strengths and difficulties questionnaire, using a predictive algorithm that has been validated in both developed and developing countries. ${ }^{2}{ }^{3}$ In this study an independent psychiatric assessment ${ }^{4}$ of randomly chosen children identified a psychiatric disorder in 23 of
41 of those whose questionnaire results suggested psychiatric disorder, compared with six of 40 of those whose results did not $\left(\chi^{2}=13.1,1 \mathrm{df}, \mathrm{P}<0.001\right)$. We assessed social class from affluence and parental education using standard Brazilian criteria-ranging from $\mathrm{A} / \mathrm{B}$ (middle class) to $\mathrm{E}$ (abject poverty and illiteracy). Maternal psychiatric disorder was predicted with the validated Brazilian cut off point on a self report questionnaire (the SRQ-20). ${ }^{5}$ Parents were asked how the child was disciplined and whether the child had witnessed marital violence.

The figure shows the univariate results and their significance. In forward conditional logistic regression, area (whether it was a favela or not) was no longer significant $(\mathrm{P}=0.84)$ once the effects of social class, maternal depression, domestic violence, and harsh discipline had been allowed for.

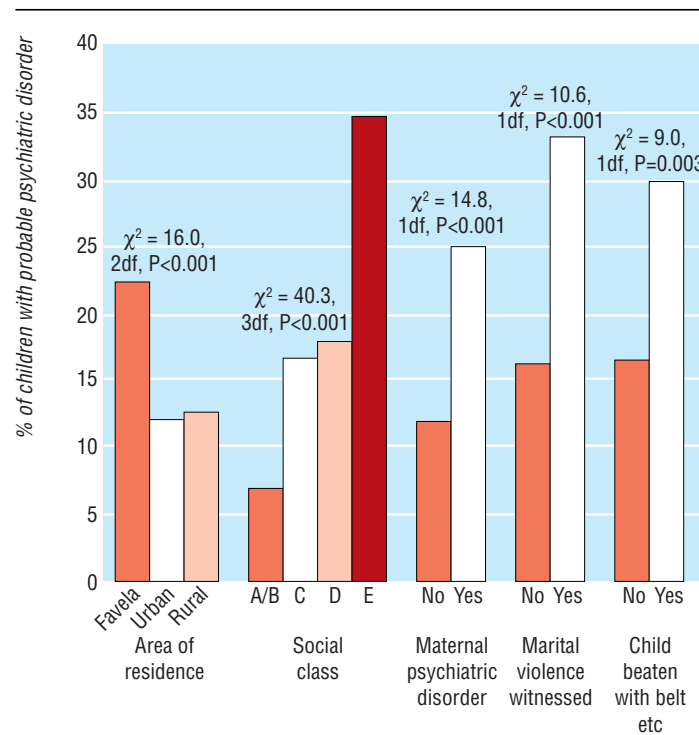

Rates of probable child psychiatric disorder according to social factors
Department of Psychiatry, University of São Paulo, São Paulo 05403-010, Brazil Bacy Fleitlich clinical researcher

Department of Child and

Adolescent Psychiatry, Institute of Psychiatry, King's College London, London SE5 8AF

Robert Goodman professor of brain and behavioural medicine

Correspondence to: R Goodman r.goodman@iop.kcl. ac.uk

BMJ 2001;323:599-600 


\section{Comment}

Poverty, maternal psychiatric illness, and family violence were all strongly associated with higher rates of probable psychiatric disorders among Brazilian 7-14 year olds. Though it is tempting to conclude that the social adversities caused the children's behavioural problems, the children's problems may have evoked maternal depression or harsh discipline. Another possibility is that the social adversities and behavioural problems both arose from unmeasured factors. The higher rate of behavioural problems in the favela could be accounted for by the associated poverty, maternal psychiatric illness, and domestic violence; future studies should investigate the possible role of social capital and social networks in buffering the impact of these social adversities. It did not need this study to identify the importance of tackling poverty, parental mental illness, or family violence in the developing world, but tackling these problems is likely to have the additional benefit of improving child mental health. Moreover, our findings help to identify marginalised groups of "at risk" children and families who should be targeted for preventive or curative services.

Contributors: Both authors devised the study and the data collection instruments and analysed the data. RG obtained the funding. BF oversaw data collection. RG is guarantor of the study.

Funding: Wellcome Trust.

Competing interests: None declared.

1 Hackett R, Hackett L. Child psychiatry across cultures. Int Rev Psychiatry 1999;11:225-35.

Goodman R, Ford T, Simmons H, Gatward R, Meltzer H. Using the strengths and difficulties questionnaire (SDQ) to screen for child psychiatric disorders in a community sample. Br J Psychiatry 2000;177:534-9.

3 Goodman R, Renfrew D, Mullick M. Predicting type of psychiatric disorder from strengths and difficulties questionnaire (SDO) scores in child

4 Goodman R, Ford T, Richards H, Gatward R, Meltzer H. The development and well-being assessment: description and initial validation of an integrated assessment of child and adolescent psychopathology. J Child Psychol Psychiatry 2000;41:645-55.

5 Mari J, Williams P. A comparison of the validity of two psychiatric screening questionnaires (GHQ-12 and SRQ-20) in Brazil, using relative operating characteristic (ROC) analysis. Psychol Med 1985;15:651-9.

(Accepted 13 June 2001)

\title{
Skin cancer surveillance in renal transplant recipients: questionnaire survey of current UK practice
}

\author{
P N Harden, S M Reece, A A Fryer, A G Smith, H M Ramsay
}

Department of Nephrology, North Staffordshire Hospital, Stoke on Trent ST4 7LN

P N Harden nephrologist

S M Reece research nurse

Department of Biochemistry, North Staffordshire Hospital

A A Fryer biochemist

Department of Dermatology, North Staffordshire

Hospital

A G Smith

dermatologist

H M Ramsay dermatologist

Correspondence to: P N Harden pnharden@ netscape.net

BMJ 2001;323:600-1

\section{bmj.com}

The questionnaire is available on the BMJ's website
The risk of non-melanoma skin cancer is increased after organ transplantation, with a prevalence and annual incidence for the United Kingdom reported at $16.5 \%$ and $7.1-10.6 \%$ respectively. ${ }^{12}$ Non-melanoma skin cancer presents at an earlier age and spreads more rapidly in people who have received a transplant than in the general population, and it often occurs at more than one site. These factors result in substantial morbidity and a sevenfold increase in mortality from the disease, although absolute death rates are low. ${ }^{3}$ The high incidence, rapid growth, and increased metastatic potential of non-melanoma skin cancer in transplant recipients justifies a surveillance programme. ${ }^{13}$ We did a survey to establish current practice in skin cancer surveillance in UK centres managing renal transplant recipients.

\section{Methods and results}

We sent a questionnaire to 65 UK centres that follow up renal transplant recipients. The questionnaire asked whether they did skin cancer surveillance, which staff did the surveillance, and what the policy was for educating patients about the risk of skin cancer.

Sixty one centres (26 surgical and 35 nephrology centres) responded, collectively managing 16264 renal transplant recipients. Among the 61 respondents, 31 were consultant nephrologists or transplant surgeons and 24 were specialist renal transplant nurses. The table shows the results of the questionnaire. On-site dermatology facilities were available in 54 centres. Thirteen centres did annual surveillance for skin cancer-by a dermatologist (2 centres), nurse practitioner (4), nephrologist or transplant surgeon (4), and a combination of nurse and nephrologist (3). Annual full skin examination (patient undressed to their underwear) was done in 12 of these 13 centres. Patients were educated about skin cancer before transplantation in 36 centres and after transplantation in 51. The mean number of transplant recipients followed up was significantly higher in surgical centres than in nephrology centres $(\mathrm{P}<0.0001)$ (table). Furthermore, a higher proportion of surgical centres provided education for patients (table). We

Skin cancer surveillance and education of transplant recipients followed up in 61 surgical and nephrology centres. Values are numbers (percentages) of centres unless stated otherwise

\begin{tabular}{lcc} 
& $\begin{array}{c}\text { Surgical centres } \\
(\mathbf{n}=\mathbf{2 6})\end{array}$ & $\begin{array}{c}\text { Nephrology } \\
\text { centres }(\mathbf{n}=35)\end{array}$ \\
\hline Mean (SD) No of recipients & $475(208)^{\star}$ & $113(67)$ \\
\hline Mean (SD) No of transplants per year & $64(32)$ & Not applicable \\
\hline Percentage of white patients & $84.2 \dagger$ & 90.2 \\
\hline $\begin{array}{l}\text { Transplant clinic taking place } \\
\text { concurrently }\end{array}$ & $25(96)$ & $20(57)$ \\
\hline On-site dermatology services & $22(85)$ & $32(91)$ \\
\hline Education of patients about skin cancer: & & \\
\hline Before transplantation & $19(73) \S$ & $17(49)$ \\
\hline After transplantation & $24(92)$ l & $27(77)$ \\
\hline Skin cancer surveillance (annual): & $5(19)$ & $8(23)$ \\
\hline Full body examination & $4(80)$ & $8(100)$ \\
\hline Screening performed by: & $1(20)$ & $1(13)$ \\
\hline Dermatologist & $1(20)$ & $3(38)$ \\
\hline$\quad$ Nephrologist or surgeon & $1(20)$ & $3(38)$ \\
\hline$\quad$ Nurse & $2(40)$ & $1(13)$ \\
\hline$\quad$ Nephrologist or nurse & $2(40)$ & $2(25)$ \\
\hline Training provided
\end{tabular}

${ }^{*} \mathrm{P}<0.0001$ (two sided $t$ test); $\mathrm{P}=0.057$ (Fisher's exact test, $1 \mathrm{df}$ ); $\S \mathrm{P}=0.051$ (Fisher's exact test, $1 \mathrm{df}$ ); $\mathbb{I P}=0.018$ (Fisher's exact test, $1 \mathrm{df}$ ). All $\mathrm{P}$ values are uncorrected for multiple comparisons. 